\title{
El medio ambiente, supeditado a la conveniencia de la economía y la política. Diagnóstico de la información a partir de sus fuentes
}

\author{
Ingurugiroa, ekonomiak eta politikak ezarritako \\ komenentzien mende. Informazioaren diagnostikoa, \\ erabilitako informazio-iturrien arabera
}

\section{The environment, subject to the convenience of the economy and policy. Diagnosis of information through news sources}

\author{
Inés Rodríguez Cruz ${ }^{1}$ \\ $M^{\mathrm{a}}$ Josefa Bezunartea Valencia ${ }^{2}$
}

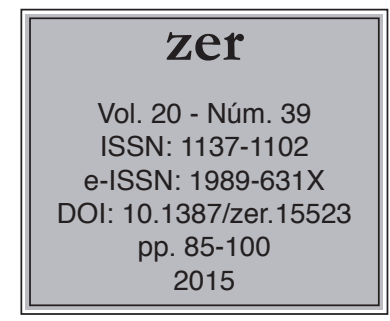

Recibido el 5 de julio de 2014, aceptado el 21 de septiembre de 2015.

\section{Resumen}

Este trabajo estudia cómo la prensa transmite a la sociedad un tema de gran sensibilidad: el medio ambiente; un asunto con muchas vertientes, a menudo contradictorias. Los contenidos periodísticos están determinados por fuentes informativas. Caracterizar las que se utilizan en las noticias ambientales proporciona una radiografía de cómo sus sectores e intereses delimitan los conocimientos a los que accede la sociedad, lo que exige un análisis desde los parámetros de un periodismo de calidad. Se han escogido dos temas que cubren facetas genuinamente conservacionistas y otras de proyección económica: Doñana y la política energética, motivo de importantes movimientos sociales.

Palabras clave: Periodismo, sociedad, medio ambiente, fuente informativa, calidad, movilización.

\footnotetext{
Universidad de Sevilla, ines.rodriguez.cruz@gmail.com

2 Universidad de Sevilla, ofa@bezunartea.net
} 


\title{
Laburpena
}

Lan honek aztertzen du nola transmititzen duen prentsak sentikortasun handiko gai bat: ingurugiroa; ertz asko -kasu askotan kontraesankorrak- dituen kontua. Informazio-iturriek mugatu egiten dituzte informazio-edukiak. Ingurugiroari buruzko albisteetan erabilitako iturriak ezaugarritu eta zerrendatzeak eskaintzen du erradiografia bat, non ikusten baita beraren sektoreak eta interesak eragina dutela gizarteak ezagutzara duen sarbidean, eta horrek berak argi erakusten du kalitatearen parametroen araberako analisia egin behar dela ingurugiroari buruzko informazioaren gainean. Lan honetan, arlo kontserbazionista hutsak eta proiekzio ekonomikodunak biltzen dituzten gai bi hautatu dira: Doñana eta politika energetikoa; gizarte-mugimendu esanguratsuak abiarazi dituzte biek ahala biek.

Gako-hitzak: Kazetaritza, gizartea, ingurugiroa, informazio-iturria, kalitatea, mobililizazioa.

\begin{abstract}
This study examines how the media communicate to society a sensitive subject: the environment; an issue with many aspects, often contradictory. News are determined by information sources. Characterize those used in environmental news provides a snapshot of how their sectors and interests define the knowledge assumed by society, which requires an analysis from the parameters of quality journalism. We have chosen two topics with important social movements: a genuinely conservationist topic, Doñana, and an economic topic, energy policy.
\end{abstract}

Keywords: Journalism, society, environment, news source, quality, mobilization. 


\section{Introducción}

El medio ambiente se integra en la política social de un país, abarcando los estamentos jurídicos, administrativos, tecnológicos, económicos y fiscales, sanitarios, etc. De ahí la responsabilidad de los medios de comunicación a la hora de transmitir acontecimientos sobre esta cuestión cuya complejidad radica, precisamente, en este carácter holístico, de forma que distintos ámbitos se ven afectados ante un mismo hecho: desde las ciencias físicas y naturales al proteccionismo de los ecosistemas, pasando por los temas de carácter energético y antinuclear, sin olvidar la presión demográfica y la competencia por los recursos o la contaminación (Esteve y Fernández, 1999; Diezhandino, 1994).

Además de la atención que se debe prestar a aspectos generales como qué lenguaje emplear o qué tratamiento periodístico deben recibir los textos, el discurso mediático se enfrenta, respecto al acceso a fuentes de información ambiental, a la dificultad de hacer llegar a la audiencia hechos complejos cuando, además, no siempre es fácil mantener el interés en estos temas con poco atractivo para los medios. En muchos casos, por ejemplo, se superponen aspectos macroeconómicos a cuestiones de consumo doméstico; o la actividad laboral, a la sostenibilidad ambiental.

La noticia debe mostrarse de forma integrada, a partir de una exposición contextualizada o con cierta continuidad narrativa. Ello obliga a poner en práctica las normas básicas de un periodismo de calidad que, como describen Kovach y Rosenstiel (2003), pasa por la obligación de informar sobre la verdad a través de un trabajo riguroso de síntesis y verificación de la noticia, con plena independencia tanto de las fuentes como de la empresa editora.

El presente artículo parte de estos supuestos: la conveniencia de acceder a fuentes $^{3}$ pertinentes que cubran todas las facetas, incluidas las técnicas, que arrastra la información ambiental, de manera que respondan en calidad y cantidad a la importancia que el propio hecho exige; y el beneficio que supone para las audiencias el que esto se haga desde una práctica y con un tratamiento periodísticos que garanticen una información de calidad, veraz y de verdadero interés para la ciudadanía.

La sociedad afirma sentirse muy interesada ${ }^{4}$ por los temas relacionados con el medio ambiente. Toca saber si las noticias reflejan la sensibilidad social con actuaciones concretas en su defensa. A través de la selección de fuentes y el modo en que se las enfrenta a los temas, el trabajo periodístico refleja, en su complejidad e integridad, los acontecimientos relacionados con el medio ambiente, desde las iniciativas interesadas de los actores con implicaciones económicas y políticas, hasta las de una ciudadanía activa con ideales conservacionistas.

\footnotetext{
3 Este estudio de fuentes forma parte de una investigación más amplia, la tesis doctoral Análisis de los casos de Doñana y las políticas energéticas en la prensa nacional y local. Información ambiental y respuesta social en España, en la que se realiza un diagnóstico del tipo de información ambiental a través del uso periodístico de las fuentes informativas.

4 El barómetro de abril de 2011 del Centro de Investigaciones Sociológicas publicaba que a la pregunta (11) sobre la adscripción ideológica un 4,5\% respondía «ecologista» como primera opción, y un 7\% más la elegía como segunda opción (11a). Igualmente, en el Ecobarómetro de Andalucía de 2010, más del $60 \%$ de los andaluces se mostraba muy preocupado por el medio ambiente. Por último, el Eurobarómetro de 2011 indicaba que el medio ambiente constituía una preocupación personal importante para más del $90 \%$.
} 
Este objetivo se acerca al de diversos estudios sobre competencia mediática en España, como el que se resalta en Sánchez y Aguaded (2013) Competencia mediática. Investigación sobre el grado de competencia de la ciudadanía en España. En él se detectaron diferencias significativas en cuanto al déficit de sentido crítico de los españoles. Otras conclusiones fueron:

a) Algunos consideraban que en los mensajes mediáticos solo hay ideología y valores cuando hay intencionalidad de transmitirlos por parte de los autores. Otros no eran conscientes de la presencia de estereotipos y de valores si estos son latentes. Y a otro grupo, consciente de esta presencia, parecía no importarle o molestarle.

b) Se detectaba una gran preocupación por la objetividad de la información mediática, así como la certeza de que hace falta confrontar las informaciones para poder tener garantías respecto a su fiabilidad.

Todos estos planteamientos nos impulsan a acercarnos a las teorías de los efectos de la comunicación, especialmente a la agenda-setting, en cuanto que explica la capacidad de los medios de decidir a qué deben prestar atención los ciudadanos.

McCombs y Shaw hablan de dos niveles (1993: 58-67). El primero se refiere a una transmisión de temas desde la agenda de los medios hacia la agenda pública, y el segundo representa los atributos que se les otorgan a esos temas.

Tanto la selección de los hechos que captan la atención como el tratamiento de los atributos son fundamentales para la determinación y construcción de la agenda pública. Los medios resaltan unos temas sobre otros, pero también señalan ciertos aspectos, personas y enfoques en relación a ellos.

Este segundo nivel relaciona la teoría de la agenda-setting con el encuadre de la información, teniendo en cuenta que el concepto abarca tanto el enfoque que se da al texto como la procedencia o fuente, y presentación, de la noticia. Por tanto, un aspecto importante es, además de la selección y jerarquización de los contenidos, los ángulos que se priorizan en detrimento de otros.

En esto radica la esencia de las dos dimensiones de la agenda-setting: los medios no solo sitúan e iluminan ciertas partes del entorno, sino que también dan significado (McCombs y Evatt, 1995: 7-32).

Aunque la teoría de agenda-setting surgiera en los años 70 del siglo pasado, con el tiempo se ha convertido en el enfoque de investigación más referido para explicar la incidencia de los medios en la formación de la opinión pública, ya que el presupuesto central sostiene que el público tiende a incluir o excluir de sus conocimientos lo que los medios incluyen o excluyen de sus contenidos: “(...) el constante énfasis en algunos temas, aspectos y problemas crea un esquema interpretativo y de conocimientos (frames) que se aplica - más o menos conscientemente- para orientar lo que el público observa" (Meyer, 2009: 15-28).

En este contexto, se va a analizar el uso de fuentes, dentro de la cobertura informativa sobre el medio ambiente en España, en torno a dos cuestiones fundamentales: la política energética española (PEE), una cuestión de interés nacional (tarifas, centrales nucleares, combustibles, renovables, medidas gubernamentales) 
y el Espacio Natural de Doñana (END), donde la población local está sumida en un debate entre conservación y desarrollo bajo la mirada de observadores internacionales (la romería de El Rocío, los pozos ilegales, el dragado del Guadalquivir, la construcción de un oleoducto).

Los medios reflejan, a través de las fuentes informativas que emplean, los intereses sociales que subyacen bajo la política energética y el desarrollo sostenible, jugando así un papel destacado al facilitar u obstaculizar la resolución de los retos que conllevan ambas cuestiones.

El estudio de las fuentes puede ayudar a comprobar si el periodismo es capaz de transmitir una información proporcionada y equitativa en toda la complejidad del hecho ambiental; o si solo recoge lo que promueven las clases política y empresarial.

Y ello sin olvidar que al otro lado del mensaje está el individuo que ha de conocer los distintos lenguajes de los medios, y que debe saber en qué consiste la transmisión de mensajes ideológicos y su valor en áreas políticas, sociales, etc. (Sánchez y Aguaded, 2013: 277).

En definitiva, el objeto de estudio se enfoca en comprobar qué tipo de fuentes informativas logran intervenir en el desarrollo de los acontecimientos sobre medio ambiente y con qué argumentos y tratamiento son presentadas, aludiendo a los elementos que definen una información de calidad (Rodríguez, 2013). Estos elementos, inspirados en el método VAP (Valor Agregado Periodístico), desarrollado en la Pontificia Universidad Católica de Chile y de Argentina ${ }^{5}$, establecen las características por las que una información sobre medio ambiente puede ser considerada de calidad.

Parten de dos premisas: la objetividad y la veracidad de los hechos narrados; para después recurrir a una redacción clara de los acontecimientos, a una contextualización en la que se aporten tanto los antecedentes como las consecuencias -muy importantes en todo hecho ambiental-, empleando conceptos bien conocidos -sin abusar de extranjerismos ni tecnicismos-, además de datos comprobables. Asimismo, la veracidad, la neutralidad, la publicación de versiones distintas de un acontecimiento son otros elementos que hacen referencia a una estructura sólida de la redacción. Por último, el empleo de declaraciones provenientes de fuentes expertas y fiables, que contrasten la información, completa el tratamiento periodístico que requiere una información ambiental de calidad.

La disponibilidad geográfica y la relevancia social de las fuentes son otros de los valores que se tienen en cuenta a la hora de decidir los temas de la agenda mediática, aunque eso implique el que un acontecimiento sea noticia por la notoriedad de sus protagonistas. La prensa se convierte así en un soporte que cede su espacio a los interlocutores para que estos dispongan de un lugar privilegiado donde manifestarse, orientando hacia ellos la información.

En ocasiones, se dan a conocer acontecimientos que no tienen valor por sí mismos, y que solo adquieren relevancia cuando son publicados en los medios. Son los pseudoacontecimientos o no acontecimientos (Fontcuberta, 1995). Como ejemplos, Toledano (2010: 201-221) apunta algunas ruedas de prensa, cumbres internacionales o visitas de un cargo público.

\footnotetext{
5 El VAP califica la calidad del valor agregado de una información respecto del grado de cumplimiento de parámetros preestablecidos, como la identificación de los hechos noticiables, la jerarquización de las noticias y la asignación de sentido respecto a los acontecimientos de los que se dan cuenta. También hace referencia a los criterios de selección de fuentes que apunten a la diversidad y a la verificación de datos.
} 
Así, no es lo mismo referirse como única fuente informativa al boletín europeo sobre el petróleo para hablar del precio de la gasolina, que recurrir a asociaciones de consumidores para debatir sobre el ahorro en combustible y la rebaja de emisiones a partir de la medida de reducción de velocidad en autovías implantada por el Gobierno de José Luis Rodríguez Zapatero; o conocer la opinión de expertos e instituciones como la Comisión Nacional del Mercado de Valores sobre la repercusión de los precios de los carburantes, no solo en la economía doméstica, sino también en la macroeconomía dEl País.

Del mismo modo, parece imprescindible confrontar los esfuerzos científicos como los de la Estación Biológica de Doñana- que, en muchos casos, son los referentes más directos para poder valorar algunos procesos ambientales, con los intereses de los agricultores o los empresarios del proyecto de oleoducto que atravesaba el parque natural: "La diversidad y especialización de las fuentes de información daría al ciudadano un perfil verdaderamente ecológico, mientras que la escasez o unidimensionalidad de las mismas convertiría los valores verdes expresados por el ciudadano en valores más volátiles o expuestos a cambios en el tratamiento informativo del medio ambiente" (Valencia, Arias y Vázquez, 2010: 31).

El resultado del periodismo institucionalizado saturado de información promovida por los intereses de los creadores de imagen de entidades públicas o privadas, como asegura Reig (2007: 96), es la detección de "un cansancio del receptor con respecto a los medios informativos". La constitución de una agenda con excesivos valores ajenos a los intereses reales de las audiencias acaba minando la credibilidad de los medios.

Sobre el uso de fuentes informativas, Diezhandino explica la importancia de trabajar con fuentes propias: "directas, justificadas, atenidas al tema, en número suficiente para contar bien la historia y expresamente mencionadas, en justa correspondencia con la necesaria credibilidad que el periodismo requiere" (2008: 18).

El estudio exige dos vertientes: tener en cuenta el uso de unas fuentes informativas, en términos de calidad -identificación correcta, atención al mayor número y variedad posible, relevancia de sus declaraciones, etc.-; y detectar la omisión de otras, con objeto de percibir la intencionalidad de la prensa en este sentido.

Y un elemento importante relacionado con los contenidos viene determinado por el origen de la información, cuestión que, por otra parte, desliza un asunto clave: quién determina la agenda de los medios. El exceso de fuentes oficiales no solo supone desequilibrar los flujos noticiosos, sino en definitiva hurtar al medio la decisión sobre los contenidos.

La determinación de cuál es el origen de la noticia supone tener delimitada de antemano su orientación: si procede de una rueda de prensa o de un comunicado, el contenido predominante responderá al interés del convocante; si por el contrario la iniciativa es del periodista, deberá responder a lo que se considera el núcleo del interés periodístico, que tiene que ver con las que se suponen necesidades informativas de la sociedad y el principio básico de qué es noticia.

La determinación de la iniciativa se detecta por el propio contenido del texto: los comunicados y las ruedas de prensa se presentan como tales, coincidiendo además la publicación en varios medios simultáneamente; los géneros periodísticos proporcionan otro índice de detección: las entrevistas y los reportajes se realizan a iniciativa del periodista. 
La proximidad ocupa uno los primeros lugares en la lista de elementos del interés noticioso; proximidad que generalmente se entiende desde la perspectiva geográfica. Así, la multa a un agricultor por uso indebido de agua subterránea en el Espacio Natural de Doñana tiene un interés circunscrito al ámbito local de Huelva. Pero la proximidad también puede interpretarse por el grado de interés inmediato para el receptor; por ejemplo, la noticia nacional sobre tarifas eléctricas sí tiene interés directo para cada uno de los miles o millones de miembros de la audiencia a lo largo y ancho de la geográfica española.

El tratamiento de la información local tiene importantes implicaciones en el modo de operar de los periodistas: los acontecimientos que tratan son conocidos por la audiencia de primera mano, lo mismo que sus protagonistas, los afectados. Resulta mucho más obligada la personalización de las informaciones y, en consecuencia, la utilización de fuentes ligadas directamente a los acontecimientos.

La elección de un tema como el Espacio Natural de Doñana, con una vertiente muy genuinamente ambiental como escenario de un ecosistema excepcional -que, además, alberga una especie emblemática como el lince ibérico-, pero generador de muchas noticias relacionadas en el interés económico-laboral del vecindario -deslindes, acuíferos utilizados fraudulentamente por los regadíos, etc.-, procuraba un caso de gran interés para analizar el comportamiento periodístico en relación a las fuentes informativas de ámbito local, en contraposición a la cuestión energética que, por el contrario trasciende totalmente las dimensiones locales, además de que aspectos económicos, políticos, estratégicos pesan más fuertemente sobre los ambientales.

\section{Objetivos y metodología}

Los objetivos que han guiado la investigación recogida en este artículo son:

- Realizar una caracterización de las fuentes informativas.

- Identificar qué aspectos del medio ambiente están más representados.

- Comprobar si el tratamiento periodístico, desde el punto de vista de las fuentes, responde a las características generales de un producto informativo de calidad sobre medio ambiente.

El cumplimiento de estos objetivos busca comprobar las hipótesis que se desglosan a continuación:

- Los medios de comunicación dan prioridad a la información ambiental que se origina desde instancias oficiales.

- Las fuentes informativas ponen el acento en cuestiones económicas y políticas cuando tratan noticias sobre medio ambiente.

- La presencia de la sociedad civil y las organizaciones en defensa del medio ambiente, como agentes movilizadores, es equilibrada respecto a las que representan los intereses económicos. 
Para el análisis se establecieron unos parámetros a partir de estudios precedentes y bibliografía existente sobre la función de los medios, la calidad informativa y la relación entre sociedad e información periodística (Bezunartea, 1996; De la Torre y Téramo, 2004; Blanco, 2008; Diezhandino, 2008; Pellegrini et al., 2011). Se siguieron también los aplicados en los trabajos que anteceden al que aquí se expone (Rodríguez, 2009, 2012 y 2013).

Para el seguimiento de la información ambiental se seleccionaron los tres diarios de mayor difusión nacional (datos del Estudio General de Medios de 2011): El País, El Mundo (edición Andalucía) y $A B C$ (edición de Sevilla); y dos diarios locales, Huelva Información y Diario de Cádiz, por ser también los de mayor tirada en las provincias en las que se ubica el Espacio Natural de Doñana. La recogida de datos se extendió a lo largo de dos años completos, 2010 y 2011, siguiendo el modelo de semana construida (Krippendorff, 1990; Stemple, 1989), técnica de muestreo aleatoria comúnmente utilizada en el análisis de contenido. Se elaboró asimismo una ficha de categorización para fuentes informativas. En dicha ficha se combinan variables propias del análisis de contenido:

- Atribución: genérica o no.

- Ámbito geográfico: local, regional, nacional, europeo.

- Tipología: testigo, fuente oficial, ONG, medio de comunicación, documental.

- Nivel de experiencia: experto o no.

- Actitud que presentaban en las respuestas: resistente, activa, reivindicativa.

- Aporte informativo: relevante o no.

Se contemplan también variables cualitativas para el análisis de los grupos sociales que más se reflejaban en estas informaciones sobre medio ambiente:

- No identificada.

- Testigos (ciudadanos, vecinos).

- Gubernamentales.

- Otras instituciones (organismos, asociaciones, entidades).

- Empresas.

- $\quad$ ONG (agentes de movilizaciones).

- Expertos.

- Documentos.

- Medios de comunicación. 
Con estos datos se logra una tipificación que permite precisamente la caracterización de las fuentes para el objetivo principal del estudio.

El corpus lo constituyeron 733 textos informativos, en los que se contabilizaron 1.350 fuentes. Los textos recogidos desde enero de 2010 a diciembre de 2011 se distribuyeron así en los cinco diarios: El País (162 artículos), El Mundo (117), ABC (112), Diario de Cádiz (118) y Huelva Información (224).

Los datos recogidos en las fichas fueron digitalizados, asignando un número de codificación a las categorías más relevantes para esta investigación. A continuación fueron tratados en una tabla de Microsoft Office Excel 2007 para facilitar la detección de errores. Finalmente, los datos fueron procesados con el programa de estadística SPSS 15.0, de donde se obtuvieron tablas de contingencia, con cruces y comparativas de variables; y gráficos y cuadros explicativos, de todo lo cual se mostrará lo más significativo.

El trabajo de análisis de contenido posterior -cuantitativo y cualitativo- completó el estudio.

Con relación a los textos seleccionados, no se han recogido aquellos en los que el hecho ambiental era anecdótico; o aquellos que, provenientes de Europa, no establecían una analogía o relación con el caso español; o aquellos puramente bursátiles, por ser cuestiones que incumben sobre todo al sector empresarial y no tienen que ver con la sensibilización ambiental de la opinión pública.

\section{Análisis y resultados}

Tabla 1. Tipo de fuentes informativas empleadas en el conjunto de textos analizados.

\begin{tabular}{|l|r|}
\hline No identificada & $4,07 \%$ \\
\hline Testigo & $2,44 \%$ \\
\hline Gubernamental & $24,52 \%$ \\
\hline Institucional & $26,52 \%$ \\
\hline Oficial privada & $18,52 \%$ \\
\hline ONG & $6,07 \%$ \\
\hline Documental & $11,26 \%$ \\
\hline Experto & $6,15 \%$ \\
\hline Total & $100 \%$ \\
\hline
\end{tabular}

En los 733 textos informativos se contabilizaron 1.350 fuentes, algunas no identificadas $(4,07 \%)$ y otras correspondientes a testigos, sector empresarial, ONG, medios de comunicación, textos o documentos, expertos y, sobre todo, gobiernos e instituciones (siendo estos últimos los valores que más se repiten).

Por periódicos, observamos que, de los diarios de tirada nacional, El País era el que da un índice más alto de fuentes informativas por noticia, con el 28,89\% de las 1.350 fuentes contabilizadas para las cinco cabeceras. Hablamos de una media de 2,41 fuentes por texto informativo; mientras que $E l M u n d o$ y $A B C$ casi estaban 
igualados, con 1,89 y 1,88 fuentes por texto informativo, respectivamente. Huelva Información tenía una media de 1,54 fuentes por texto; y Diario de Cádiz, de 1,55.

Tabla 2. Punto de vista predominante.

\begin{tabular}{|l|l|}
\hline Económico & 189 \\
\hline Político & 191 \\
\hline Científ./Téc./Tecnológ. & 143 \\
\hline Seguridad/salud/bienestar & 107 \\
\hline Legal/Normativo & 42 \\
\hline Ambiental antrocéntrico & 87 \\
\hline
\end{tabular}

Las informaciones publicadas provenían mayoritariamente de ámbitos institucionales y gubernamentales y de empresas del sector que ofrecían sus noticas a los medios. Por otra parte, también las noticias que habían sido promovidas por los periodistas contaban, con carácter preferente con las fuentes oficiales: gubernamentales, de instituciones públicas y de empresas marcadas por el interés político y económico; apenas había representación de científicos, de expertos o de responsables de organizaciones defensoras del medio ambiente. Así, los puntos de vista predominantes para END y PEE eran el económico y político frente al ambiental.

Las informaciones no reflejaban una amplia representación social -pues se movían siempre entre los mismos entes interesados-, aunque el aporte informativo de las fuentes empleadas era, en general, muy relevante el $77,19 \%$ de las ocasiones; poco relevante, el 20,07\% de las veces; e irrelevante, en el 2,74\% de los casos.

Se observa que solo las fuentes de los ámbitos gubernamental e institucional suman un 51,04\% de las analizadas, mientras que el resto (testigos, sector empresarial, ONG, medios, fuentes documentales y expertos) no llegan al $45 \%$.

Para hablar sobre PEE, los periodistas recurren mayormente al boletín petrolero de la Unión Europea y a la Comisión Europea; a miembros del Gobierno central (Alfredo Pérez Rubalcaba, Miguel Sebastián y Manuel Chaves) y de la oposición (Mariano Rajoy y María Dolores de Cospedal); al Instituto Nacional de Estadística, la Comisión Nacional de la Energía y al Consejo de Seguridad Nuclear. En el caso de END, las fuentes más asiduas son Francisco Bella Galán, como alcalde de Ayamonte (municipio onubense ubicado en este espacio protegido); y miembros del Gobierno andaluz (José Antonio Griñán, José Juan Díaz Trillo).

Fuera del ámbito gubernamental e institucional, las fuentes informativas que más aparecen en estos dos años de análisis son las compañías energéticas (Abengoa, Acciona, Endesa, Gas Natural, Iberdrola), las asociaciones agrarias y sindicales y, en menor proporción, las ONG, como Greenpeace, Ecologistas en Acción, WWF, Asociación Andaluza para la Defensa de los Animales (Asanda), Asociación para la Defensa y el Estudio de la Naturaleza (Agaden).

El comportamiento de las cinco cabeceras es homogéneo en cuanto a la distribución de fuentes, con predominio de las públicas en detrimento de las empresas privadas del sector y, sobre todo, de ONG ambientales y de expertos.

No aparecen las voces de los grupos que tienden a la acción, los movilizadores, que suelen ser más contestatarios, buscando escenarios cercanos a las bases sociales 
(debates universitarios, manifestaciones), que representan las posturas conservacionistas, ni expertos que expongan los aspectos ecológicos. La presencia de estos grupos se basa apenas en una declaración a pie de calle o en escasas ruedas de prensa: no consiguen traspasar las barreras de los medios de comunicación.

Así pues, la radiografía de los temas ambientales denota un encuadre de marcado trazo político-económico-empresarial, en el que apenas hay vestigios de alerta sobre los peligros que se ciernen sobre el medio ambiente.

Tabla 3. Origen de la información.

\begin{tabular}{|l|}
\hline No se refleja: $12,01 \%$ \\
\hline Otro medio de comunicación: $0,41 \%$ \\
\hline Agencia de noticias: $13,78 \%$ \\
\hline Fuente interesada: $48,57 \%$ \\
\hline Fuente documental: $7,09 \%$ \\
\hline Revista científica: $0,14 \%$ \\
\hline Periódico: $18,01 \%$ \\
\hline
\end{tabular}

La medición de la iniciativa periodística, cuestión de gran relevancia respecto de los contenidos informativos, puso en evidencia diferencias reseñables en el tratamiento de los temas sobresalientes estudiados. Así:

- Energías renovables: 14,81\%

- Energía nuclear: 27,4\%

- Políticas energéticas: 30,99\%

Mientras que el número de noticias en las que las fuentes fueron las promotoras se repartió de la siguiente forma:

- Energías renovables: 48,15\%

- Energía nuclear: 38,36\%

- Políticas energéticas: 35,21\%

El tema del agua -la explotación de acuíferos, el uso de pesticidas, las captaciones ilegales- fue el predominante en las noticias sobre Doñana; pero, pese al ingrediente de proximidad y al interés mucho más directo de la noticia, solo el 20\% de las noticias obedecieron a la iniciativa periodística.

Como se observa en la siguiente tabla, solo el $18 \%$ de las noticias corresponden a iniciativa del periodista.

\subsection{Carácter de la respuesta social}

Aunque los temas por los que apostaba cada cabecera variaban, los grupos sociales destacados en ellos eran los mismos: solo el 6,6\% de los 733 textos analizados hacía 
referencia a un grupo movilizador (Asociación contra la Contaminación Lumínica, Club Doñana, etc.) que, casi siempre, iba acompañado de otros actores empresariales o de la Administración.

El de las centrales nucleares era el asunto en el que los periodistas daban más cabida a grupos movilizadores como ONG o grupos vecinales, o a expertos e investigadores. Algunos ejemplos son:

- «Villar de Cañas quiere ser nuclear» (28/1/2010), en el que los ciudadanos se manifestaban a favor de la central de residuos.

- «Protesta para pedir el cierre de las centrales» $(A B C, 9 / 5 / 2011)$, un breve sin fuentes informativas, pero en el que se reflejaba una manifestación de 30 organizaciones ecologistas.

- «Concentración en Barcelona» (El Mundo, 28/1/2011), «Manifestaciones en Guadalajara, Soria y Cáceres contra el almacén nuclear» $(E l$ Mundo, 21/2/2010). De nuevo, asociaciones ecologistas y ciudadanos protagonizaban estas acciones sociales.

El Diario de Cádiz, además, recogió las reivindicaciones de una asociación ciudadana ante la intención de un ayuntamiento de construir un parque eólico marino:

- «Más de 11.000 firmas contra el parque eólico marino de Chipiona» $(20 / 1 / 2010)$.

- «La plataforma contra el parque eólico se manifiesta hoy en Chipiona» $(28 / 8 / 2010)$.

Quizás se podría pensar que los diarios de edición local serían más sensibles a una reacción activa de la sociedad, por cercanía y accesibilidad a las fuentes interesadas, pero en realidad no ha sido así ni para estos ni para los diarios nacionales: $E l$ País, 9,18\%; ABC, 5,17\%; El Mundo, 3,80\%; Huelva Información, 0,87\%; Diario de Cádiz, 4,35\%. Estos porcentajes representan a informaciones en las que se hacían referencia a ciudadanos o ecologistas, a sus movilizaciones, protestas o, en fin, manifestaciones de cualquier naturaleza.

\subsection{Exposición institucional}

$\mathrm{Al}$ igual que es importante conocer los sectores sociales que se reflejan en la prensa, también lo es el modo en el que los periodistas lo abordan, cómo se acercan a él. Así, no es lo mismo que un periodista redacte de manera expositiva, más aséptica podíamos decir, una información en la que no participe ninguna fuente interesada (por ejemplo, una noticia sobre una resolución judicial por la caza de un lince ibérico, complementada con una referencia a la norma ambiental), o que el periodista elabore una noticia a partir de las declaraciones de una y otra parte; o que informe sobre una acción reivindicativa ciudadana. 
En la mayoría de las informaciones analizadas predomina la exposición de medidas y decisiones del Gobierno o de las instituciones, acompañadas de las reacciones de los sectores afectados, reflejando en muy pocas ocasiones una reivindicación social. He aquí dos ejemplos excepcionales:

- «Costas contra todos por Doñana» (5/9/2010), noticia publicada en El País sobre las alegaciones contra el deslinde del Parque Nacional de Doñana promovido por el Ministerio de Medio Ambiente. Esta acción del gobierno promovió un importante revuelo entre los propietarios de los terrenos. El diario dio voz a los perjudicados por la norma de costas.

- «Unas 3.000 personas se manifiestan en Valladolid contra el almacén nuclear» (12/4/2010), publicada en $A B C$. En ella intervenían grupos ecologistas, ciudadanos manifestándose, la Administración pública y las propias centrales nucleares.

En resumen, las informaciones sobre END y PEE eran meras exposiciones de declaraciones de representantes de administraciones e instituciones públicas y privadas, aunque pudieran corresponder a intereses contrapuestos siguiendo la máxima de apariencia de neutralidad y con mínima presencia de agentes defensores del medio ambiente.

\subsection{Fuentes locales}

Tabla 4. Área geográfica de fuentes informativas [\%].

\begin{tabular}{|l|c|c|c|c|c|c|}
\hline & $\begin{array}{l}\text { No } \\
\text { identificada }\end{array}$ & Local & Regional & Nacional & Europea & Internacional \\
\hline EI País & 7,18 & 16,67 & 11,79 & 55,90 & 4,36 & 4,10 \\
\hline ABC & 8,10 & 28,57 & 18,10 & 35,71 & 5,24 & 4,29 \\
\hline EI Mundo & 12,22 & 12,22 & 12,22 & 52,49 & 4,98 & 5,88 \\
\hline $\begin{array}{l}\text { Huelva } \\
\text { Información }\end{array}$ & 6,36 & 35,55 & 21,39 & 31,50 & 3,47 & 1,73 \\
\hline $\begin{array}{l}\text { Diario de } \\
\text { Cádiz }\end{array}$ & 4,37 & 34,97 & 13,66 & 39,34 & 6,01 & 1,64 \\
\hline
\end{tabular}

En contra de lo que cabía presumir, los periódicos locales analizados Diario de Cádiz y Huelva Información como se observa en la Tabla 3, no aprovecharon la proximidad de las fuentes en el tratamiento de las noticias producidas en Doñana., si bien Huelva Información destaca en el uso de actores locales como protagonistas de sus noticias.

El interés social de la noticia también se puede ver influenciado por la actitud que muestran estas fuentes informativas, es decir, por el modo en que se acercan a las audiencias a través de la prensa. 
Tabla 5. Actitud de las fuentes informativas [\%].

\begin{tabular}{|l|c|c|c|c|}
\hline & No reseñable & Resistente & Activa & Reivindicativa \\
\hline EI País & 16,15 & 1,28 & 76,41 & 6,15 \\
\hline ABC & 29,05 & 0,00 & 68,57 & 2,38 \\
\hline EI Mundo & 23,53 & 0,90 & 74,21 & 1,36 \\
\hline Huelva Información & 19,08 & 0,00 & 80,92 & 0,00 \\
\hline Diario de Cádiz & 19,67 & 0,00 & 79,23 & 1,09 \\
\hline
\end{tabular}

En la Tabla 5 vemos que la práctica totalidad de las fuentes presentaban una actitud activa, lo cual es consecuente con el hecho de que tomaran la iniciativa; las fuentes renuentes son las que son forzadas por los periodistas a dar datos o pronunciarse cuando no lo desean. Esto es, abundan las declaraciones de quienes tienen interés en que se publique su versión de los hechos, en proporcinar datos que les favorecen o en que se dé a conocer la acción de la que son protagonistas.

\section{Conclusiones}

Tras este recorrido por el uso de fuentes de información ambiental por parte de cinco diarios españoles, se puede confirmar la unidimensionalidad de fuentes que caracteriza la cobertura periodística de diarios tanto nacionales como locales sobre el medio ambiente. Aunque la media de fuentes informativas por noticia no es baja $(1,84)$, es destacable el hecho de que el 69,56\% de las fuentes estudiadas sean exclusivamente gubernamentales e institucionales (más públicas que privadas).

Se cumple, pues, la primera de las hipótesis, que apuntaba que los medios dan prioridad a la información ambiental que se origina desde instancias oficiales: pública $(26,52 \%)$, gubernamental $(24,52 \%)$ y privada $(18,52 \%)$. Y ello tratándose tanto de diarios de tirada nacional, considerados tradicionalmente como prensa de referencia, como de diarios locales, donde tienen la oportunidad de acceder a fuentes directamente afectadas por medidas judiciales o administrativas, como es el caso de los deslindes o la utilización del agua subterránea, entre otros. Así, Diario de Cádiz es la cabecera analizada que hace más uso de fuentes institucionales (privadas, públicas y gubernamentales), con un $74,86 \%$; seguida a muy poca distancia de Huelva Información (71,39\%) y El País (71,28\%).

La segunda hipótesis de partida era la apuesta por el carácter político y económico de la cobertura periodística sobre el medio ambiente, debido al tipo de fuentes que intervienen en las informaciones. Los datos del análisis lo confirman, puesto que de todos los textos estudiados, tan solo el 8,32\% recogía un punto de vista ambiental. En el caso de la PEE, este porcentaje era del 1,44\% y en el de Doñana, del 30,1\%.

A tenor de los resultados, los rotativos que menos han apostado por esta vía fueron Diario de Cádiz (5,08\%) y El Mundo $(6,84 \%)$. Aun con estos datos, no se quiere decir que no existiera en las informaciones analizadas una referencia ambiental, sino que el medio ambiente no suponía el enfoque principal.

Un factor que puede explicar esta práctica periodística es el reducido espacio que ocupan las informaciones sobre medio ambiente, o el hecho de que en su mayoría sean traslaciones de ruedas de prensa convocadas por organismos e instituciones. 
A estos números hay que añadir también la cantidad de fuentes informativas no identificadas $(4,07 \%)$, aparte del 7,85\% de noticias en las que no se hacía referencia a fuente alguna.

Como consecuencia de lo apuntado hasta ahora, vemos que la tercera hipótesis planteada en este trabajo no se cumple. La sociedad civil y las ONG, como agentes movilizadores, así como los expertos, no equilibran la presión de los intereses económicos o políticos en torno al medio ambiente.

Solo el 6,15\% de los casos eran fuentes expertas; el 6,07\%, ONG; y el 11,26\%, fuentes documentales. Y esto es así, en general, para todos los diarios (no existen diferencias considerables entre la prensa nacional y local) y para todas las temáticas.

En conjunto, no se le puede dar a la información sobre medio ambiente la calificación de periodismo de calidad, fundamentalmente porque no responde a algunos de los requerimientos para obtenerla: faltan las versiones que contextualicen todos los ángulos del tema del que se informa y las consecuencias -por ejemplo de las políticas energéticas contra las energías renovables, o del deterioro del ecosistema por la falta agua en Doñana-; además, la diversidad de fuentes debe ser una exigencia y está en la mano de los profesionales el buscarlas cuando estas no aparecen espontáneamente.

\section{Referencias bibliográficas}

BEZUNARTEA, O. (1996). El uso de las declaraciones en la información política. Estudios de Periodística IV, 69-104. Pontevedra: Diputación de Pontevedra.

BLANCO, M.M. (2008). Modelos de análisis para el estudio crítico de la prensa. Madrid: Ediciones Internacionales Universitarias.

DE LA TORRE, L.; Téramo, M. T. (2004). La noticia en el espejo. Medición de la calidad periodística: la información y su público. Buenos Aires: Educa.

DIEZHANDINO, M. P. (Coord.) (2008). Periodismo en la era de Internet. Claves para entender la situación actual de la información periodística en España. Madrid: Colección Fundación Telefónica; Ariel.

DIEZHANDINO, M. P. (1994). Periodismo de servicio: la utilidad como complemento informativo en Time, Newsweek y U.S. News and World Report, y unos apuntes del caso español. Barcelona: Bosch.

ELÍAS, C. (2001): "Periodismo especializado en medio ambiente: el caso Doñana como paradigma de manipulación informativa". En Ámbitos, n 6 .

ESTEVE, F.; Fernández, J. (1999). Áreas de especialización periodística. Madrid: Fragua.

FERNÁNDEZ PARRATT, S. (2006). Medios de comunicación y medio ambiente. Madrid: Fragua.

FERNÁNDEZ REYES, R. (2003). "En torno al debate sobre la definición del periodismo ambiental". En Ámbitos, no 9-10.

FONTCUBERTA, M. (1995). La noticia. Pistas para percibir El Mundo. Barcelona: Ediciones Paidós Ibérica. 
KOVACH, B.; Rosenstiel, T. (2003). Los elementos del periodismo. (A. Diéguez Rodríguez Trad.). Madrid: Ediciones El País.

LÓPEZ, X. (2004). Desafíos de la comunicación local: guía para la práctica de la información en los ámbitos de proximidad. Sevilla: Comunicación Social. Ediciones y Publicaciones.

McCOMBS, M.; Evatt, D. (1995). Los temas y los aspectos: explorando una nueva dimensión de la agenda setting. Comunicación y sociedad, Vol. VIII, 1, 7-32.

McCOMBS, M. E.; Shaw, D. L. (1993). The Evolution of Agenda-Setting Research: Twenty-Five Years in the Marketplace of Ideas. Journal of Communication, Vol. 43, 2, 58-67.

MEYER, J. A. (2009). Establecimiento de agendas en medios de comunicación: Repercusiones del escándalo mediático Marín-Nacif-Cacho. Revista Latina de Comunicación Social, 64, 15-28. (doi: 10.4185/RLCS-64-2009-801-15-28) (19-03-2014).

ODRIOZOLA, J. (2011). "La construcción informativa de la catástrofe del Prestige. El abuso de las fuentes institucionales". En Anàlisi no 44, pp. 77-92.

ODRIOZOLA, J. (2012). "Evolución y características del periodismo ambiental". En Fernández, J., Rubio, A. y Sanz, C. (eds.). Prensa y Periodismo Especializado 5. Guadalajara: Asociación de la prensa de Guadalajara, pp. 249-259.

PELEGRINI, S. et al. (2011). Valor agregado periodístico. La apuesta por la calidad de las noticias. Santiago de Chile: Ediciones Universidad Católica de Chile.

REIG, R. (2007). El periodista en la telaraña. Nueva economía, comunicación, periodismo, públicos. Barcelona: Anthropos.

RODRÍGUEZ, I. (2012). Análisis cuantitativo y calidad de la información sobre medio ambiente en la prensa española. Presentado en Comunicación y Riegos: Comunicaciones del III Congreso Internacional Asociación Española de Investigación de la Comunicación (Tarragona, 18-20 de enero de 2012). [S.1.]: Asociación Española de Investigación de la Comunicación.

RODRÍGUEZ, I. (2009). Análisis cuantitativo y calidad de la información sobre el medio ambiente en la prensa española. Disertación doctoral sin publicar. Universidad de Sevilla, Facultad de Comunicación.

RODRÍGUEZ, I. (2013). La calidad de la información sobre medio ambiente. En Gómez, J.L. et al., La calidad periodística. Teorías, investigaciones y sugerencias profesionales. (pp. 177-190). Castelló de la Plana: Publicacions de la Unversitat Jaume I.

SÁNCHEZ, J.; Aguaded, J. I. (2013): El grado de competencia mediática en la ciudadanía andaluza. Estudios sobre el mensaje periodístico, Vol. 19, 1, 265-280. Madrid, Servicio de Publicaciones de la Universidad Complutense. (doi: http:// dx.doi.org/10.5209/rev_ESMP.2013.v19.n1.42521) (27-04-2014).

Toledano, S. (2010). Obsoleta manipulación: elementos reales, virtuales y ficticios para una nueva concepción de la información. Communication Journal, 1, 201-221.

VALENCIA, Á.; Arias, M.; Vázquez, R. (2010). Ciudadanía y conciencia medioambiental en España. Opiniones y actitudes, 67. Madrid: Centro de Investigaciones Sociológicas.

VICENTE, M. (2009). "Environmental communication research in Spanish". En Media Development 3, pp. 1-8. 